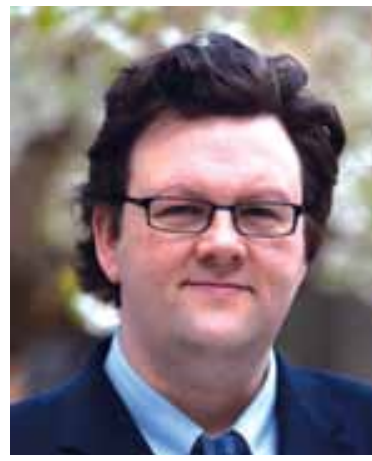

LEON CRUICKSHANK

Reader in Design

Lancaster University, UK

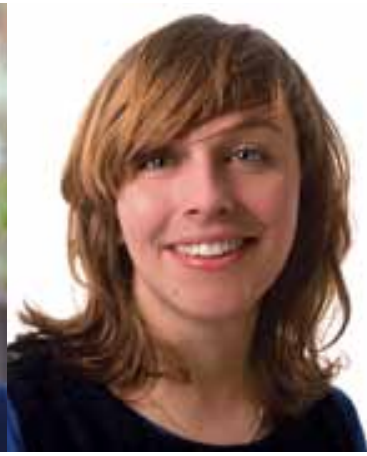

GEMMA COUPE

PROUD Design Manger,

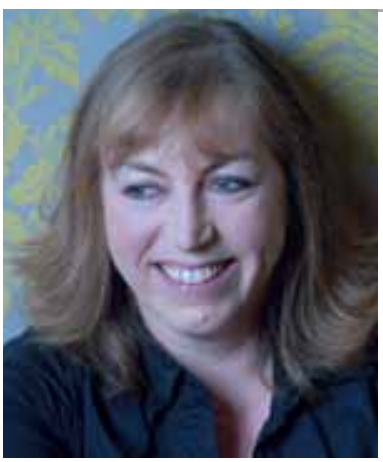

DEE HENNESSY

Co-Designer,

\title{
Co-Design:
}

\section{FUNDAMENTAL ISSUES}

AND GUIDELINES FOR

DESIGNERS: Beyond the Castle Case Study

BY LEON CRUICKSHANK, GEMMA COUPE \& DEE HENNESSY

Keyworlds:

Co-Design, Knowledge Exchange, Participatory design, Public Sector, Public Engagement 


\section{ABSTRACT}

In this paper we describe a high profile project to reimagine a large green space in the heart of the city of Lancaster in the UK. This co-design project involved professional designers, but also 2500 people with 700 of these making an active co-design contribution. This project forms the basis of a discussion of how we used a series of events to help participants reach their full creative co-design potential.

From this case study we go on to develop a framework of recommendations to help designers reflect on their normal practice and how they need to operate within a codesign project. These recommendations seek to maximise the benefits of this approach and produce good design outcomes. This framework has been evaluated in a series of international workshops in the UK, Belgium and the Netherlands.

\section{INTRODUCTION}

Co-Design is a well-established approach to creative practice, especially in the public sector. It is often used as an umbrella term for participatory, co-creation and open design processes. In fact following Sanders' position (E. Sanders \& Stappers, 2008) we would argue that co-design is a subset of a wider notion of co-creation. Co-Design has its roots in participatory design developed in Scandinavia in the 1970s and in the seminal 'Design Participation' conference held by the Design Research Society in the UK in 1971 (E. Sanders \& Stappers, 2008)

We are currently seeing a transformation in design studies, processes and methods that is placing a new emphasis on co-design. This is fuelled by an erosion of the designer as the gatekeeper between means of production and consumers, this is evident in the spread of rapid manufacturing technology (e.g. 3D printing) but also in the popularity of services to 'design your own' company web site. In these and many other cases the designer's role as an intermediary between the means of production and the 'user' is becoming less pronounced. The move to make design more strategic by people such as Roger Martin (Martin, 2009) but also a move to go beyond a tokenistic engagement with non-designers involved in design projects (Lee, 2008). In this paper we use the definition used by both the UK Design Council and The European Design Leadership Board in their report 'Design for Prosperity and Growth'. They both define co-design as: A community centred methodology that designers use to enable people who will be served by a design outcome to participate in designing solutions to their problems. (Koskinen \& Thomson, 2012)

\section{PUBLIC SPACE CO-DESIGN CASE STUDIES}

In practice Co-design approaches vary greatly from being close to consultation and information gathering to facilitating people in generating their own ideas and solutions. For example, scenario techniques can be used to identify the interests of different stakeholders, enabling them to participate in different stages of planning and design (Tress $\&$ Tress, 2003). To 'accommodate a non design orientated population' the use of visualisation co-design techniques is well documented (Al-Kodmany, 1999, Sanches \& Frankel, 2010) .

Co-design processes have also been known to fail, for example 'the process failed at the stage of active participation of the citizens' due to unimaginative methods to engage citizens in the co-design of an urban square in Ypzgat, Turkey (Dede, Dikmen, \& Ayten, 2012).

As a response to this, interesting, innovative, open, co-design processes are emerging. Lee highlights the gap between sociological research conducted by 'outsiders' and contributions made by 'insiders'. Professional designers in co-design often use toolkits that allow them to form a process that enables others to be creative in their own way (Lee, 2008). Using social networking technologies new approaches such as online 'city-citizen' projects are emerging where a software infrastructure takes on the role of the 'Urban Mediator' (Botero \& Saad-sulonen, 2008), a response to bottom-up city led innovation, which were 'often not provided by the city administration or connected to it' (Botero \& Saad-sulonen, 2008). This contrasts with storytelling approaches used to co-design public environments and services in Helsinki which focus on metropolitan railway experiences (Mattelmaki T \& Vaajakallio, 2012a)

The long-term benefits of co-design have been recognised for example in the Demos international survey on co-design (Bradwell \& Marr, 2008), and more specifically in the development of a building standard in Norway. After twenty five years the inclusive design co-operation between the municipality and the organisation for disabled people has led to reshaped recreation areas which are better for all, and a new building standard that is attracting international interest (Co-design in Smart Cities, a guide for municapalities from Smart Cities, 2011).

\section{OUR CO-DESIGN APPROACH}

The Beyond the Castle (BTC) case study described here was part of a larger European project looking at how co-design can help communities improve public spaces. This larger project called PROUD (People, Researchers Organisations 
Using co-Design) is funded through the EU by a program called INTERREG IV.

Our aim in BTC working with a group of designers was to create a 'scaffolding' which enabled people with a very broad range of experience and expertise to have a creative (not just informational) input into the design process (E. B. Sanders, 2002).

This required both flexibility and strong support, flexibility was required to allow creative input in many different forms, not just in the traditional ways designers are trained. So, for example, participants did not have to be able to visualise ideas for them to be given value, flexibility was also required to enable disparate contributions to meaningfully connect to each other. Finally flexibility was essential to allow for the whole picture to change over the duration of the project.

Structures of support were needed to give the process forward momentum as it is much easier to be creative when there is something to respond to, rather than the intimidating challenge of a blank page. The overall emphasis BTC placed on flexibility was quite risky, as the quote below demonstrates, for the council really taking the openness seriously (while still making a concrete outcome feasible) made the designers we employed, the council stakeholders and other professional groups uncomfortable.

As one City Council public realm officer said, 'It was quite difficult, but when I got the understanding, could see where the potential was. We tend to say this was the leap of faith, it doesn't sit very well within the Council, because we're used to having set outcomes and controlling it and obviously we're answerable to the public, so normally we would say 'right, we'll spend six months on this and this is what we're getting at the end', and there was a massive leap of faith for this, which was quite obvious mid-way through when certain partners had to step back and just go 'right, we trust you on this, you're going to produce something for us that's going to work', and just run with it'

This tension was also reflected by our designers who found the lack of control inherent to the co-design processes we were using to be highly challenging. For example this comment was taken from an interview with Lotte Van Wulfften Palthe, one of the co-designers employed by PROUD for BTC.

'I'm finding it difficult and I want to test what for me is the limit or the boundary when I still think it's design. I think it still is after doing this project now, it's just that it's that part of design that we're creating objects that are aesthetically really well thought out but that's not the issue that we're facing at the moment, that's not really important, so that's not what I want to focus on, because it's not fulfilling'.

Further, Andy Walmlsey, a experienced designer but someone new to co-design said 'Oh man, the first few weeks were really tough, I kept jumping in with ideas and trying to control conversations the way I would normally do with a client. It took me a while to get to grips with the openness of co-design. I still find it difficult now to be honest but the results are there to see, there is a lot of good stuff in the exhibition'.

We were aware that this would not be an easy project for any of the participants, partly because we were looking to stretch our collective understanding of co-design. Also as we will see towards the end of the case study, moving people out of their comfort zone was an essential component in the successful outcomes of the project.

\section{PROUD AND BEYOND THE CASTLE}

Lancaster is a city in the north west of the UK and is dominated by a hill with a castle on it. One side of the castle is five minutes' walk from the central shopping area of the city. On the other side there is an undeveloped, rather overgrown area of around $500 \mathrm{~m} 2$ sloping steeply down to the River Lune. It is a space used by cyclists, dog walkers, groups of teenagers and sometimes as an illegal camping site for homeless people. This area has national significance in archaeological terms and it is strictly protected from any building works.

Until recently the castle was used as a low security prison. The owners (Duchy of Lancaster, that is the UK Queen's private estate) have decided to develop the castle into a tourist destination. Although they own the castle building itself, the surrounding land is owned by the City Council, so there is a requirement for close collaboration between City Council and the Duchy of Lancaster. This and the fact that the roots of the trees on the site are starting to damage the concealed archaeology has created the imperative to rethink and develop the area.

This placed pressure on the City Council to develop a coherent plan for the site that had both political and community support. This posed a challenge, as throughout the project we talked to people who considered the standard council consultation process to be more of an exercise in 
communicating the decisions already made, than genuinely seeking ideas and opinions. As one senior environmental officer says of BTC:

'We were aware that there'd been some previous plans and consultations done which, I think, some people felt were imposed upon them, without a proper meaningful consultation. One of our prime objectives, to go back and do it in a different way, and come up with solutions for the site that everyone could kind of buy into, PROUD seemed to tick most of those boxes'

With a traditional consultation process already started, the PROUD project was invited to undertake a co-design project to help produce this plan. A first review of the consultation events so far uncovered a strong request to 'stop consulting with us!' There was a very consistent cohort of people attending the consultation meetings and they were now disillusioned by hearing the same ideas and observations with little sign of this having any effect. Analysing the results of the consultation undertaken so far, we came up with some key conclusions.

$\searrow$ There were some repeated themes coming out from some key stakeholders, including history, accessibility and environmental aspects of the site.

$\checkmark$ We needed to engage with a wider range of people, not just the people with the time and inclination to attend consultation events.

$\searrow$ We needed new ways of engaging these new people

The last two points were problematic for the council officers who were involved with the project. Although we had spoken to them about the openness of a co-design approach, this was the point where they realised that they were not going to be in control of the process, and for some members of the council team this was very stressful indeed.

In this early stage of the project giving the council some positive reinforcement was very difficult because we decided that we had to pause the public face of the process to recruit five designers or creatives and with them co-design a new process for Beyond the Castle project. This meant the council were left somewhat in limbo; we were not able to tell them what the outcome of the process would be, how we would be doing it or who would be involved.

Once we were making and undertaking successful public events, it was much easier for the people we were working with directly in the council to reassure their managers (and the layers of management above those managers) that we would end up with something interesting. In this respect good documentation and an up-to-date website (http:// imagination.lancaster.ac.uk/activities/Beyond_Castle) were crucial. As our key contact in the City Council said

'I found the photographs that you did particularly useful, when you emailed out the photographs of what happened at an event was good, because they were good quality but you could see people getting involved at different ages and 'oh did you see the photographs?' 'Oh yeah, yeah, they were really good'. So even if they [managers] couldn't attend, they saw the photographs and it was more like a reassurance, yeah, it's okay, you're engaging in enough people with a broad background, they're getting involved. And I think that's where it changed.'

It took three months of behind-the-scenes effort to get to this point as we procured designers from a range of backgrounds, including a landscape designer and local resident to provide expert knowledge, a branding expert to help understand the identity of the space, an expert in participatory narratives to explore non-visual co-design possibilities and finally a skilled facilitator.

In addition to the designers that we recruited, we also employed a co-design manager for PROUD. Her role was not to be creative but to focus on the organisation and management of the process and to make sure the logistics; materials, networks and connections were in place. This is another important aspect of the structuring or scaffolding that supports a project. The co-design manager was also responsible for mapping the vision of the designers to the overall aims of the project and, where appropriate, shaping the activities to keep them on track.

The first thing we did with the creatives was to get them together for two full days of discussion, planning and familiarisation. It was here that they developed (with some other inputs) a common conception of co-design and the needs of a co-design program for the PROUD project.

Towards the end of these two days a plan was established with five events that working together would constitute the co-design for BTC. These allowed people to contribute creatively, using the creative scale described by Lindsay and Sanderson (E Sanders \& Stapers, 2008). BTC contributions ranged from relatively simple 'doing' to in-depth 'creating' contributions. The five events were

1 Beyond the Castle: this was an awareness-raising event where a corner of the central shopping square in Lancaster 
was transformed into a representation of the area 'Beyond the Castle'. Passers-by were invited to document both the things they did in the area and how it could be improved on a three-metre model of the area. See Figs. 1 and 2

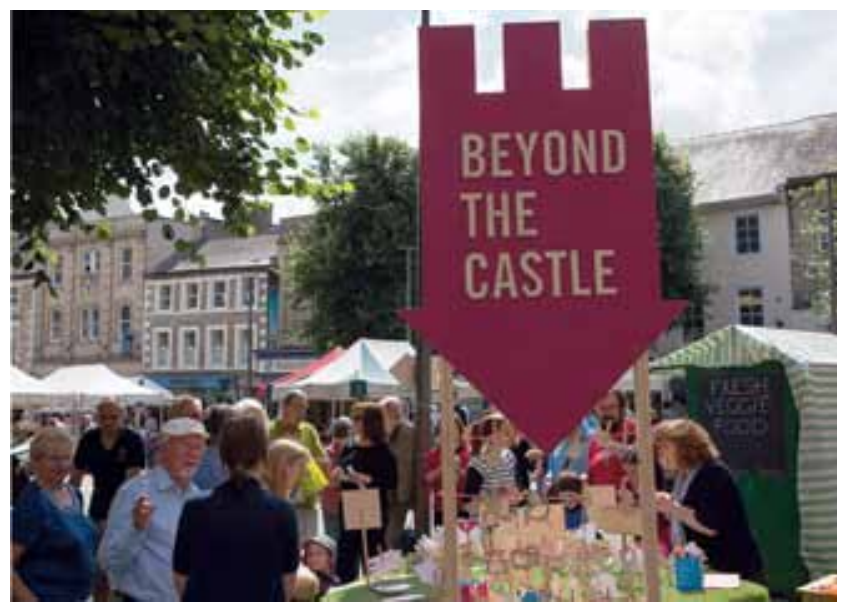

Fig. 1 Market Square Activity

2 Just Imagine All The Stories: This was eight interconnected activities running in the green space behind the Castle. Using co-design through story telling this included bringing the past into the present with the aid of a living Roman centurion and a swamp fairy. This was designed to elicit a deeper interaction aimed at families and the young at heart. See figures 3 and 4

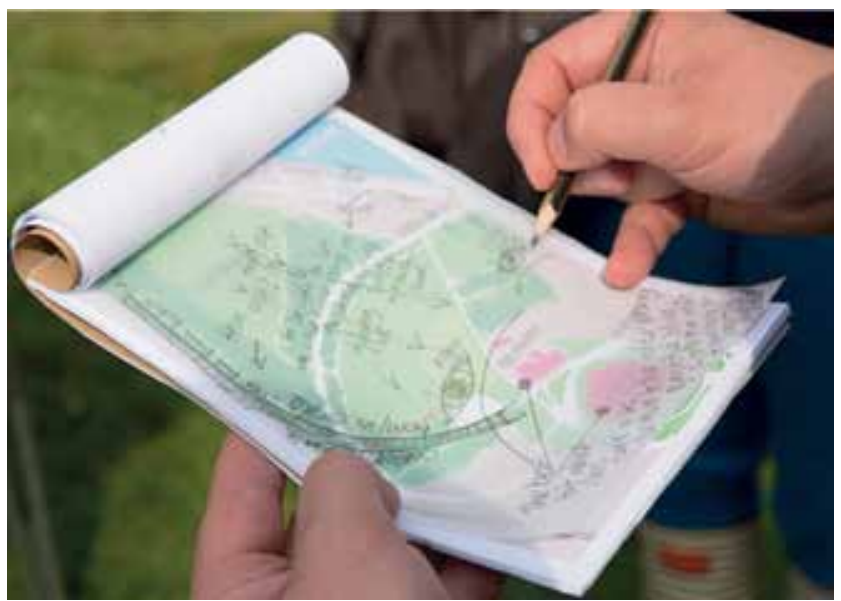

Fig 3. Participants documenting their story journey

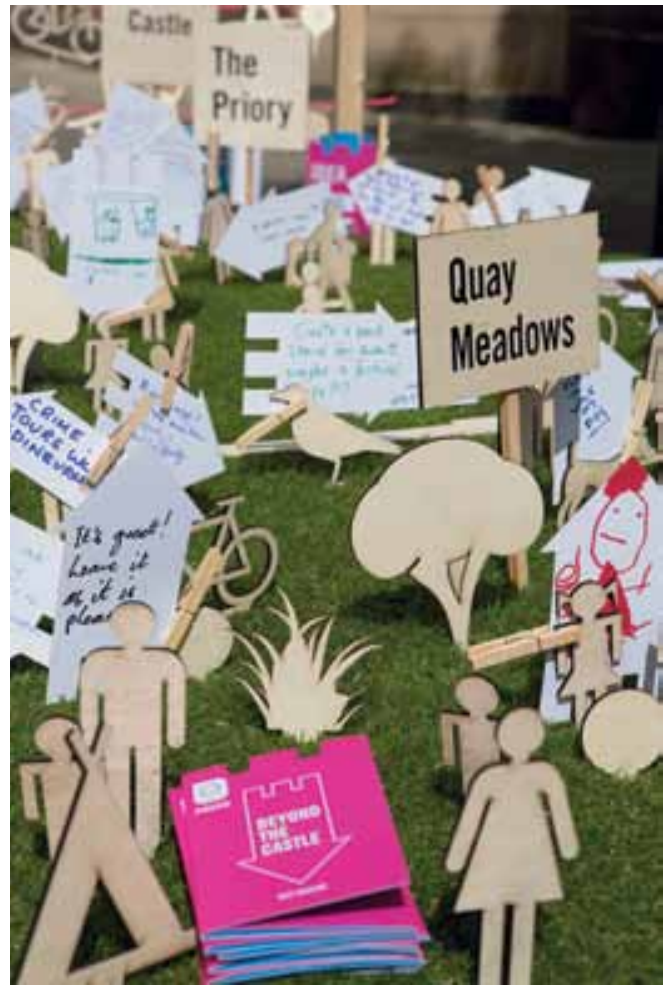

Fig. 2 'Doing level' creative contribution

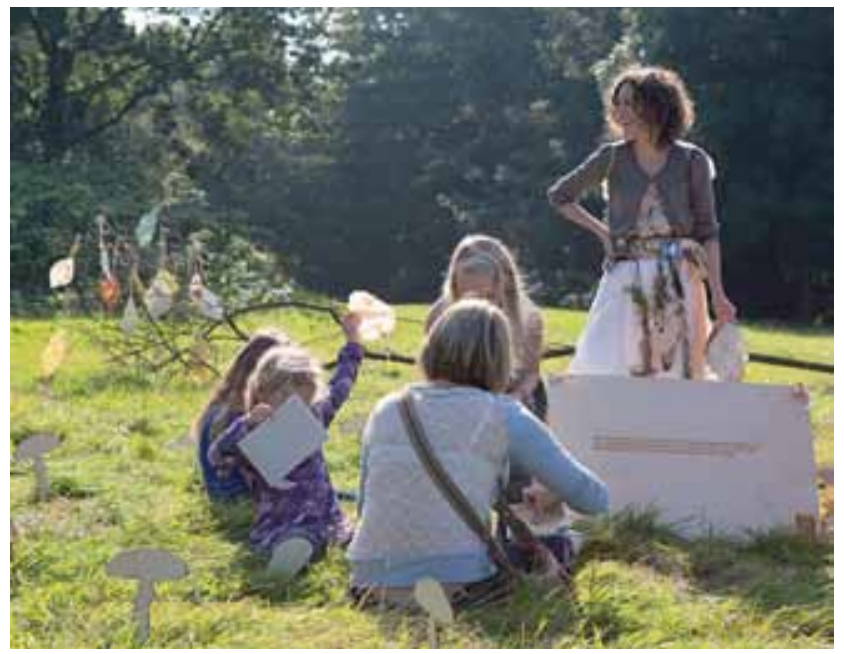

Fig. 4 The Swamp fairy, traps people until they have a good idea

3 Just Imagine the Shape of the Park:

Here participants mapped and modelled possible developments in the Beyond the Castle area. Participants ranged in age from three to 92. In this open access event 
many people stayed for over 30 minutes working on their models. See figure 5 .

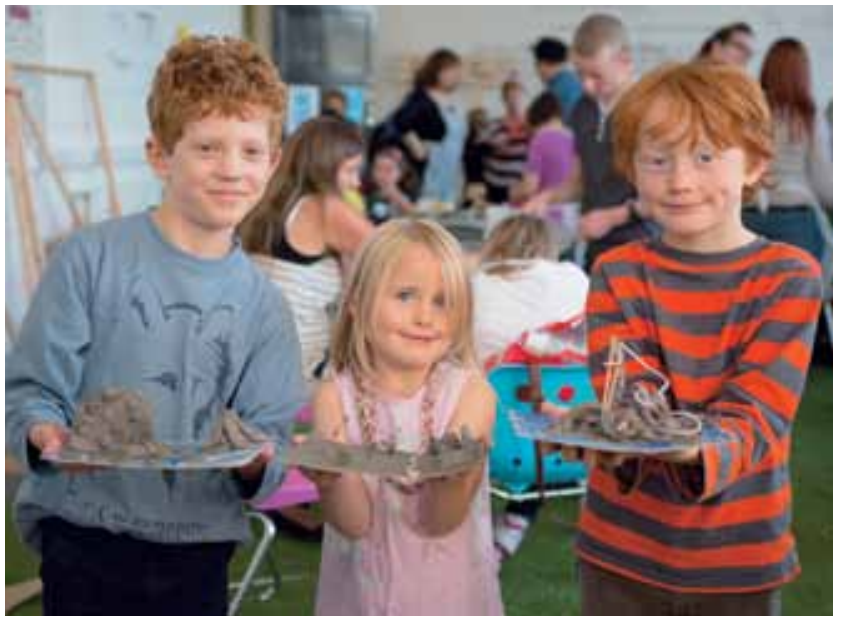

Fig. 5 Model making interventions

4 Visioning: This was a different type of event, as all the others were completely open to the public without any registration. Here the 15 most active contributors helped make sense of the more than 1000 ideas contributed from previous events and helped curate the next stages of the process, see figure 6. In an intensively facilitated and designed event the group identified and ranked 80 or so more general or emotional values that needed to be kept in mind; these were labelled the 'don't forgets' (e.g. don't

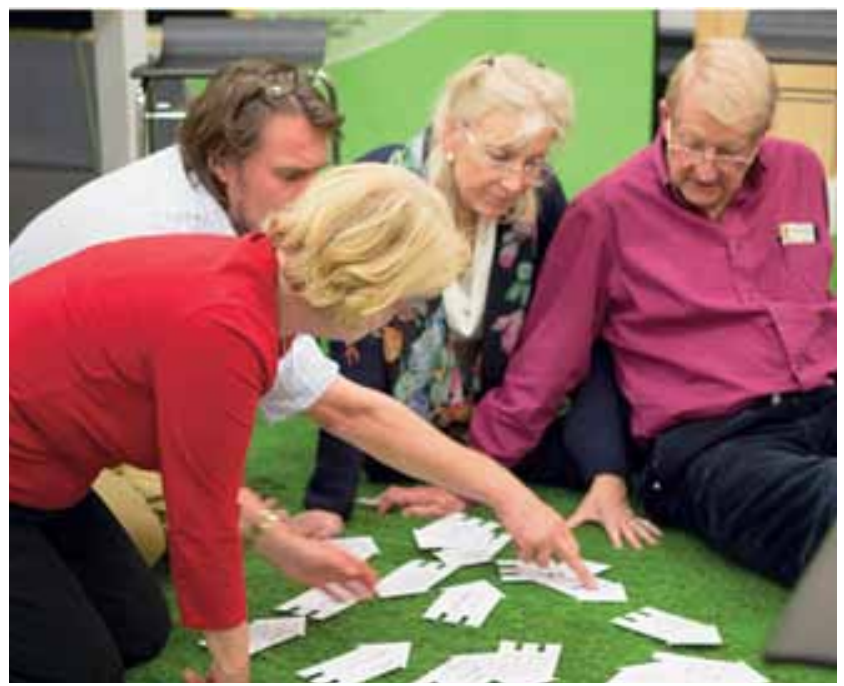

Fig. 6 Analysing and curating all the ideas suggested so far forget to keep people involved in the process). The group also undertook a thematic analysis of the ideas gathered so far; the group identified common factors within themes (e.g. History or Cultural activity).

5 Interactive Co-Design Exhibition: This is a good example of really designing an activity with the usual elements of divergent, convergent thinking, prototyping and so on, as we had no clear idea of what this would be even four weeks before the exhibition opened. Working with a range of participants the designers came up with what would immerse visitors to the exhibition in the city centre and in all the ideas submitted so far, and then constructed an interactive 'scaffoldings for experiencing' (E. Sanders \& Stappers, 2008) that would give them the opportunity to really co-design. This was the point where participants could move into 'create' mode with the insights from the previous phases informing the ideas (Mattelmaki T \& Vaajakallio, 2012b).

The resulting mechanism had people selecting one of the 'don't forgets' and one element of thematic analysis and selecting a prompting question (e.g. how could this be implemented for less than $£ 1000$ ) to come up with suggestions that were documented on cardboard boxes. On average, participants spent over 40 minutes developing their suggestions, sometimes in conversation with volunteers at the exhibition, but more often on their own, see figures 7-10).

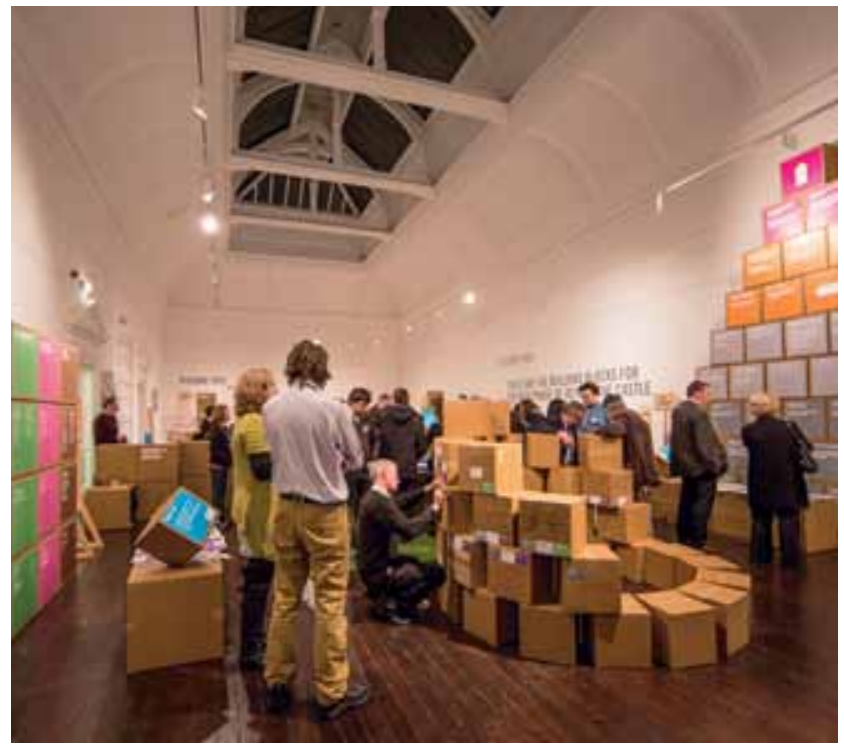

Fig. 7 The interactive co-design exhibition 

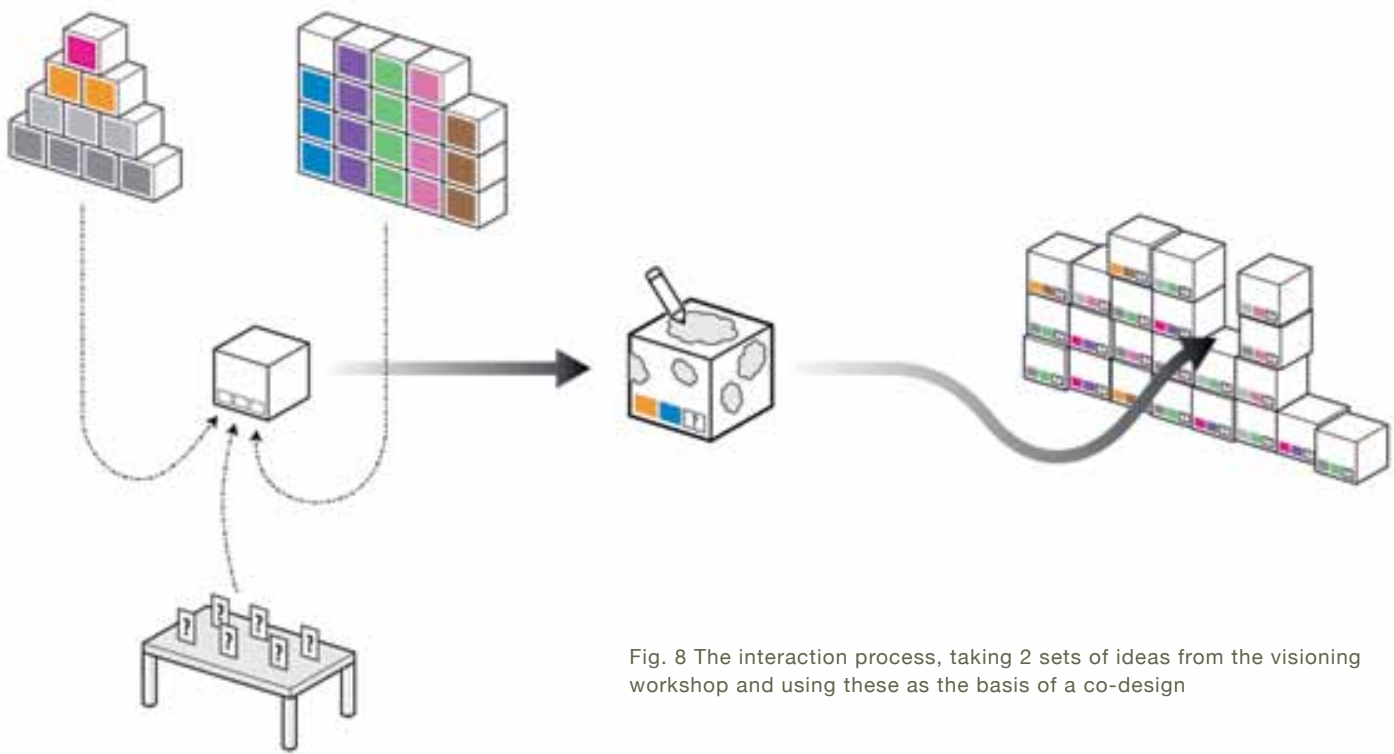

Fig. 8 The interaction process, taking 2 sets of ideas from the visioning workshop and using these as the basis of a co-design

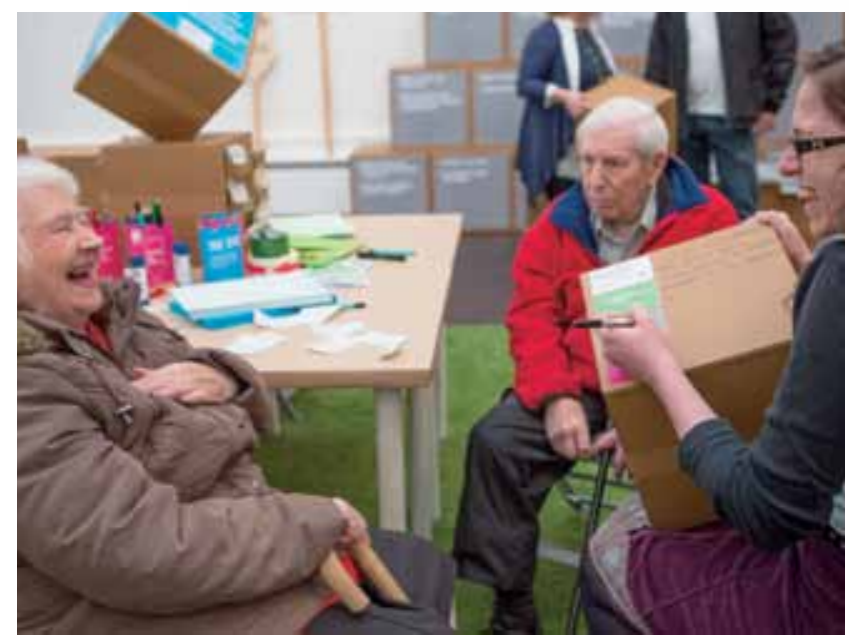

Fig. 9 Co-designing with two of our 'over 90' participants

These co-design suggestions (fig. 11) are notable for the range and sophistication of the ideas developed by individuals. Largely these were good new ideas from the perspective of our Council colleagues. After the ideas were transcribed and analysed these detailed ideas (and the large range of preparatory ideas, comments and suggestions) were presented to the City Council in a substantial report (see http://imagination.lancs.ac.uk/outcomes/Beyond_Castle_Imagining_Future). This will form the brief for an upcoming master planning process, through this BTC will set the agenda for development at least until 2020. The level of public engage-

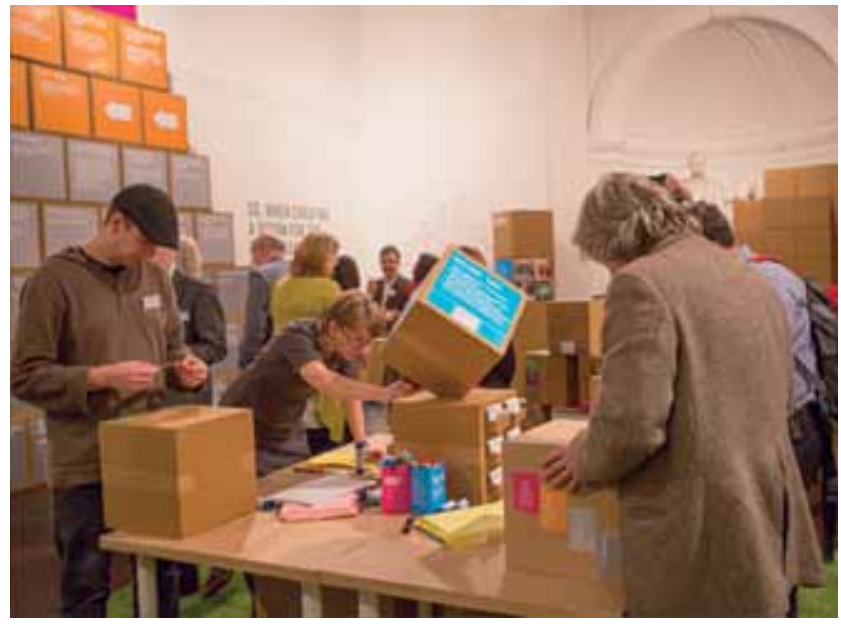

Fig. 10 Individuals Co-designing

ment, the innovative nature of the process, the quality of the responses and the outcomes of the process have a legitimacy and a weight that is hard to dismiss.

\section{FRAMEWORK}

Some designers (including some in BTC) find setting aside their role as 'an expert in charge' very difficult in the co-design process. In response to this we developed an interactive workshop and 8 fundamental guidelines for designers in co-design projects. We tested these through a series of interactive workshops in the UK, Belgium and Netherlands. They were refined into the following: 


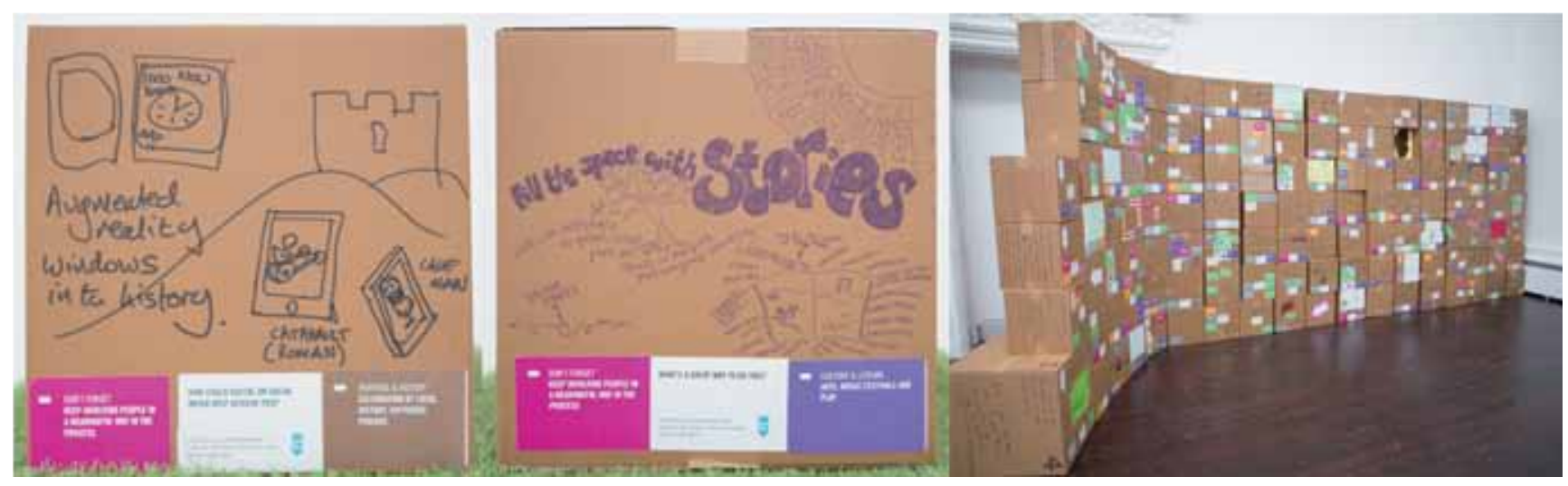

Fig. 11 Some individual and the collective co-design responses

1. Agree how the success of the project will be recognised How will progress be recognised, when is the job complete? These could be long-term strategic aims or much more tactical short-term goals or (most likely) a combination of these.

\section{Move in and beyond your normal design practice} To avoid 'design by committee' participants have to be able to change the way they think about problems and solutions. Individuals cannot just have an ideal position then compromise until the compromises overlap and agreement is reached but with everyone equally unhappy. This applies to designers just as much to others (who for designers may have very unusual approaches to solving problems). This change in process demands a degree of reflection and willingness to take risks with new processes, that is not present in all designers.

3. Involve and respect lots of people in the ideas generating parts of the process

Acknowledging that non-designers can have great ideas is at the core of all co-design. We all have the potential to contribute to the idea generating and development phase of the process. This is not to say we all have the same creative ability, but rather that creative ability will not reside only in the professional designer.

\section{Use the expertise of all participants in the process}

In addition to creativity, participants all have expertise that should be welcomed in and used to inform the process. The real challenge is to get as many people involved as possible in a capacity that enables them to make the most positive contribution. In BTC we did this through a broad programme of events designed to allow participants to make expert contributions, e.g. an archaeologist gave a spontaneous and unexpected 20-minute talk during one of the co-design events.

\section{Let everyone be creative in their own way}

Most designers are inculcated with a particular set of methods and approaches that frame their perspective and creative process. Generally this is associated with visualisation and divergent/convergent thinking (Lawson \& Dorst, 2009). Designers need to accept in their hearts as well as heads that there are other ways to be creative, and that just because these may not fit with their own expectations, this does not reduce their value. Actually, the intelligent designer should realise that understanding and using these frames is a very good way of improving their own practice. 6. Explore and challenge assumptions Some of these assumptions may be symptoms of hidden, highly relevant, or in Von Hippel's terms, 'sticky' information (Von Hippel, 1994) that would be useful to share explicitly. Equally these assumptions may not necessarily hold true in all situations and may not be the stumbling block they first appear.

\section{Expect to go beyond the average}

If co-design processes are to flourish in the mainstream of design the notion that the results of these processes are less strong than conventional design has to be addressed. There are two aspects to this; firstly co-design processes themselves should be designed to be extraordinary, fun, dynamic actions that will maximise the potential for people to contribute. Secondly the outcomes of these processes, whether products, services, knowledge and understanding, have to hold up in 
terms of quality and effectiveness for the given context. 8. Bring the process to the best possible conclusion with the best possible design outcome

Acknowledge the contribution made by participants. Contributions should be documented and participants should not be left 'dangling' with opinions or ideas excluded from things like project documentation.

\section{PEER EVALUATION}

These principles were used as the basis for a series of interactive workshops with designers, entrepreneurs and public sector workers across Europe. These lasted for one day each and were undertaken in Kortrijk (Belgium), Eindhoven (the Netherlands) and Lancaster (UK). In total this involved 63 people with an equal mix of designers, entrepreneurs and public sector workers, all of whom were experienced but not expert in co-design. Through these workshops and the debates engendered within them we 'stress tested' the principles.

We also undertook an evaluation process to test the principles directly. We gathered together an expert panel of 14 co-design academics, practitioners and managers to evaluate these guiding principles. The evaluation took place in Luxembourg with experts working in pairs, identifying challenges or problems with the assertions, then more positive responses and finally through a general discussion. The process was 'self documenting' see Figure 11.

The outcomes of this evaluation were generally very positive. There were a few contentious points, especially around the principle to 'Move in, out and beyond your normal design practice'. For the group the key question was around the notion of 'normal design practice'. This is clearly contingent on the traditions of the designers involved in the process, making this somewhat too vague. Related to this was also an acknowledgement that not all designers are suited to co-design.

There was a proposal to change 'Use the expertise of all participants in the process' to 'Channel the expertise of all participants in the process', this seems more inclusive but highlights something a little more significant, while 'channelling' is better than 'using' it still has an air of a hidden controlling hand, perhaps 'Include the expertise of all participants in the process' is a better way to describe the sentiment of this principle.

The group were unanimous in their approval of the call to go beyond the average. There was a strong feedback from the group to ensure co-design projects are both distinctive, and also of high quality, and that without this, even the most inclusive and empowering processes were suspect.

This leads us to the final and key recommendation, that evaluation be a more important component of co-design processes throughout the activity and absolutely not left until the end of the project. This resonates with the need to assess, and where appropriate challenge assumptions, and with the establishment of desired outcomes of the project at the start of an intervention. This raises important issues that

Fig. 11 Experts reviewing the co-design principles

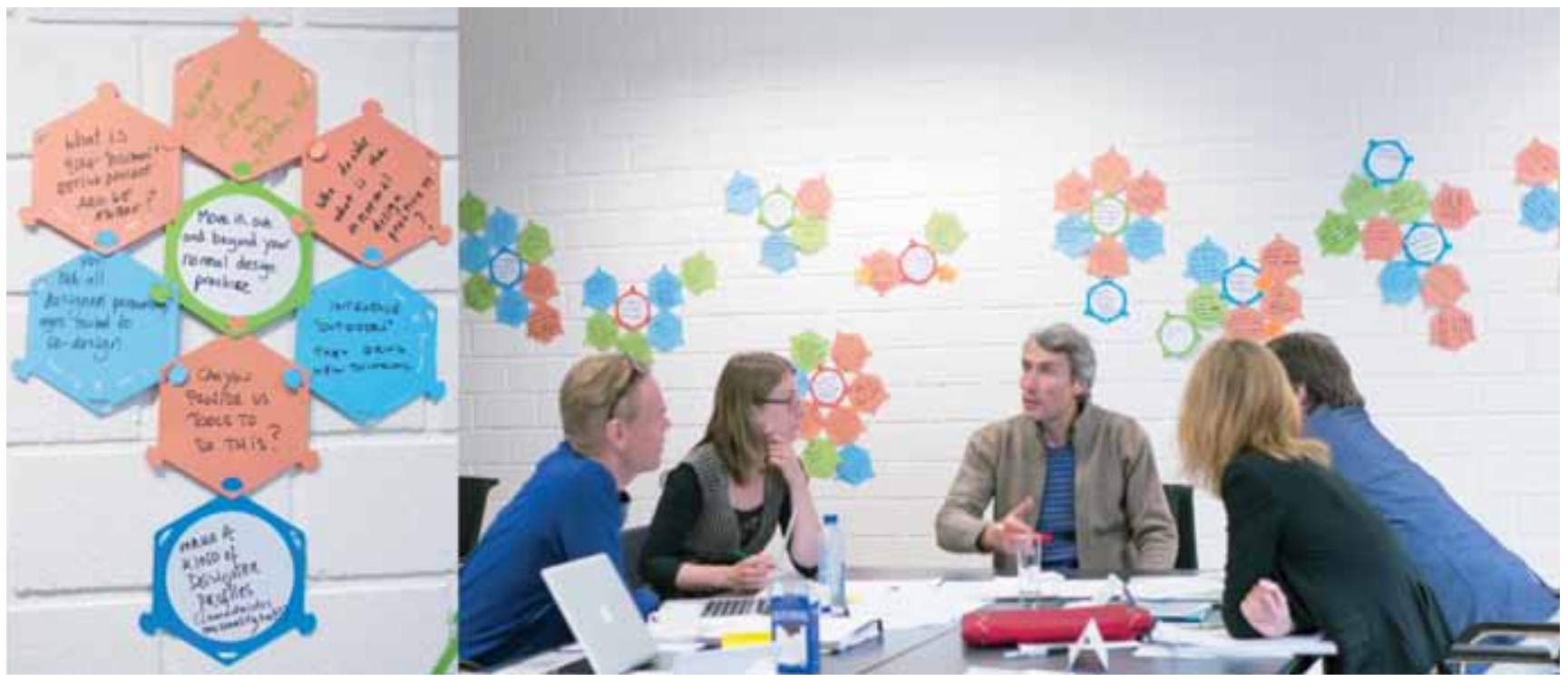


are often neglected in open and co-design projects; how to evaluate while recognising and respecting the delicate nature of new ideas in a process is an open question that needs further study.

\section{CONCLUSION}

In this paper we have shown through the Beyond The Castle project the potential benefits of an open, emergent approach to co-design that allows participants to express themselves creatively across a whole spectrum of engagement ranging from lightweight, 'doing' contributions up to creative interventions where individuals concentrate for a long period and create very high-quality co-design suggestions. We have also shown that this can be difficult for both designers and public service workers who are used to much more predictable, controlled interventions where they are very much in a hierarchical position.

The recommendations that grew out of this project were intended to challenge the implicitly hierarchical position designers often take on creative projects. These recommendations were also intended to promote active reflection by designers on their processes and assumptions and how these relate to the assumptions and creative processes of others. It is through this type of reflection (and responding to these reflections) that new types of co-design processes and codesigners will develop, ensuring all co-design participants have the opportunity to make their best possible contribution in co-design processes.

There remain a number of critical issues within co-design as an approach that are both inclusive and that result in better outcomes. These centre on the definition and recognition of good outcomes (that will be specific to a particular context) and also to the interplay between designers disciplinary training, methods and wider co-design principles.

\section{REFERENCES}

Al-Kodmany, K. (1999) Using visualization techniques for enhancing public participation in planning and design: process, implementation, and evaluation. Landscape and Urban Planning, 45(1), 37-45. doi:10.1016/S01692046(99)00024-9

Botero, A., \& Saad-sulonen, J. (2008) Co-designing for new city-citizen interaction possibilities : weaving prototypes and interventions in the design and development of Urban Mediator. In Proceedings of the Tenth Anniversary Conference on Partto Design (pp. 269-272). Indiana:
University of Indianapolis.

Bradwell, P., \& Marr, S. (2008) making the most of collaboration an international survey of public service co-design: DEMOS Report 23. Retrieved from www.engage.hscni.net/library/demos paper.pdf Co-design in Smart Cities, a guide for municapalities from Smart Cities. (2011) Retrieved from http://www.smartcities. info/files/Co-Design in Smart Cities.pdf

Dede, O. M., D kmen, Ç. B., \& Ayten, A. M. (2012) A new approach for participative urban design: An urban design study of Cumburiyet urban square in Yozgat Turkey. Journal of Geography and Regional Planning, 5(5), 122-131. doi:10.5897/JGRP11.129

Koskinen, T., \& Thomson, M. (2012) Design for Growth \& Prosperity.

Lawson, B., \& Dorst, K. (2009) Design Expertise. Taylor \& Francis.

Lee, Y. (2008) Design participation tactics: the challenges and new roles for designers in the co-design process. CoDesign, 4(1), 31-50. doi:10.1080/15710880701875613 Martin, R. L. (2009) The Design of Business: Why Design Thinking is the Next Competitive Advantage. Harvard Business Press (p. 191). Cambridge Massachusetts: Harvard Business School Press. Retrieved from www.amazon. com/Design-Business-Thinking-Competitive-Advantage/ $\mathrm{dp} / 1422177807$

Mattelmaki. T, \& Vaajakallio. K (2012a). Spice: Understanding Public Spaces Through Narative Concept Design. Retrieved from http:/designresearch.aalto.fi/groups/encore/ wp-content/uploads/2012/06/esseekokoelma_valmis1.pdf Mattelmaki. T, \& Vaajakallio. K (2012b) Spice: Understanding Public Spaces Through Narative Concept Design. Sanches, M. G., \& Frankel, L. (2010) Co-design in Public Spaces : an Interdisciplinary Approach to Street Furniture Development. In drs2010 Unmontreal. Retrieved from http://www.designresearchsociety.org/docs-procs/DRS2010/ PDF/105.pdf

Sanders, E. B. (2002) Scaffolds for Experiencing in the New Design Space. In Institute for Information Design Japan (Ed.), Information Design. Graphic-Sha Publishing Co Ltd. Sanders, E., \& Stappers, P. (2008) Co creation and the new landscapes of design. Co Design, 4(1), 5-18.

Tress, B., \& Tress, G. (2003) Scenario visualisation for participatory landscape planning - a study from Denmark. Landscape and Urban Planning, 64(3), 161-178. doi:10.1016/ S0169-2046(02)00219-0

Von Hippel, E. (1994) “Sticky Problem Information" and Solving : the Locus of Implications for Innovation. 